\title{
Mechanical Performance of Carbon-epoxy Laminates Part I: Quasi-static and Impact Bending Properties
}

\author{
José Ricardo Tarpani*, Marcelo Tadeu Milan, Dirceu Spinelli, Waldek Wladimir Bose \\ Materials, Aeronautics and Automotive Engineering Department, \\ Engineering School of São Carlos, The University of São Paulo - Brazil
}

Received: November 5, 2003; Revised: December 29, 2005

\begin{abstract}
In Part I of this study, quasi-static and impact bending properties of four aeronautical grade carbon-epoxy laminates have been determined and compared. Materials tested were unidirectional cross-ply (tape) and bidirectional woven textile (fabric) carbon fiber lay-up architectures, impregnated with standard and rubbertoughened resins, respectively, giving rise to $1.5 \mathrm{~mm}$-thick laminates. Quasi-static mechanical properties assessed in transversal mode loading were modulus of elasticity, flexural strength and tenacity at the maximum load, whereas the net absorbed energy was determined under translaminar impact conditions. Two-dimensional woven carbon fiber reinforcements embedded in a rubber-toughened matrix presented the best mechanical performance under static loading. Under dynamic loading conditions, woven fiber fabric pre-forms were favorably sensitive to increasing impact energies regardless the nature of the employed epoxy resin. However, it was concluded that great care should be taken with this material within the low energy impact regimen.
\end{abstract}

Keywords: carbon-epoxy laminates, composite materials, mechanical properties

\section{Introduction}

According to Harrington and Reed ${ }^{1}$, polymer matrix composite materials constituted by continuous carbon fibers embedded in a thermosetting epoxy resin were first developed to satisfy high standards required in aircraft design. By mixing in these two distinct phases, fibers and resin, and adopting different fiber configurations new and better mechanical properties can be obtained. In the fabrication of aeronautical components and structures, the specific mechanical performance of the employed material, i.e., property/density ratio, is a major requisite since fuel saving and payload improvements constitute fundamental criteria for the operational optimization of the fleet. Therefore, high specific stiffness and mechanical strength are basic requirements that have to be fulfilled by carbon-epoxy laminates, considering all the loading modes which aircraft parts experience during service conditions, e.g., tension, bending, fatigue and impact. Notwithstanding the relatively low impact resistance of carbon-epoxy composites, $\mathrm{Niu}^{2,3}$, Middleton ${ }^{4}$, Agarwal and Broutman ${ }^{5}$, and Hoskin and Baker ${ }^{6}$ state that the high specific mechanical strength displayed under distinct loading conditions, especially fatigue, still grant them the status of the broadest used composite material in civil and military aircraft industries.

Part I of this work investigates the quasi-static and impact bending performance of four carbon-epoxy laminates utilized in the Brazilian aeronautical industry, whereas Part $\mathrm{II}^{7}$ evaluates their quasi-static and fatigue tensile properties.

In both studies, special attention is paid on the effects of the employed epoxy resins (standard $v s$. rubber-toughened, with the latter cured at higher temperature and pressure) on the overall performance of the laminates. It is worth of mention that the latter resin is much more expensive (approximately threefold) than the former one. On the same token, it is needless to say that higher cure temperature and pressure increase the overall cost of the lamination process, by adding energy and time to the fabrication cycle. Since end users of composite laminated materials, e.g., aeronautical industry, are very concerned on the effective cost of raw materials, which can be established in a performance/cost ratio basis, this work intends to generate some subsides for a more rigorous selection of engineered composite materials, eventually leading to considerable cost savings.

\section{Materials and Test Specimens}

Four types of carbon-epoxy composite laminates, previously cured in autoclave (vacuum bag) and supplied by the manufacturer as semi-finished $1.5 \mathrm{~mm}$-thick test specimens, were evaluated. In these, unidirectional carbon tapes were disposed according to the angle-ply $[0 / 90]_{2 S}$ lay-up, whereas bidirectional eight-harness satin weave followed the $[0 / 90]_{4}$ pattern. Two different classes of epoxy resin were employed: a standard grade cured at $120^{\circ} \mathrm{C} / 420 \mathrm{kPa}(60 \mathrm{psi})$, and a rubber-toughened grade cured at $180{ }^{\circ} \mathrm{C} / 700 \mathrm{kPa}$ (100 psi).

Table 1 describes the materials tested.

Typical optical micrographs of cross-sections of the composite laminates are shown in Figure 1.

As expected, higher cure temperature and pressure, as well as closer compacted fiber fabric architecture give rise to thinner laminates. It is also expected that the thinner the laminate, the higher is its consolidation degree, the lower is its void content, and so the better its mechanical performance is likely to be.

The testpiece geometry adopted for quasi-static three-point bend (3PB) testing was full-thickness tablets with in-plane dimensions $65.0 \mathrm{~mm} \times 27.5 \mathrm{~mm}$ (Figure 2a), in which the load is applied in a transversal (i.e., trans-thickness) manner. Similar specimens were used for translaminar 3PB impact testing, except that a $0.45 \mathrm{~mm}$ wide and $17.5 \mathrm{~mm}$ long notch was diamond-saw machined in the centerline of the specimens, along their width (Figure $2 b$ ), in order to induce a preferential plane for the fracture path. 
Table 1. Résumé of materials tested.

\begin{tabular}{cccc}
\hline Material code & Fiber phase array & Cure temperature $\left({ }^{\circ} \mathrm{C}\right) /$ pressure $(\mathrm{kPa})$ & Range of thickness $(\mathrm{mm})$ \\
\hline TP120 (Figure 1a) & Tape & $120 / 420$ (standard epoxy resin) & $1.61-1.65$ \\
TP180 (Figure 1b) & Tape & $180 / 700$ (rubber-toughened) & $1.51-1.52$ \\
FB120 (Figure 1c) & Fabric & $120 / 420$ (standard epoxy resin) & $1.53-1.54$ \\
FB180 (Figure 1d) & Fabric & $180 / 700$ (rubber-toughened) & $1.46-1.47$ \\
\hline
\end{tabular}

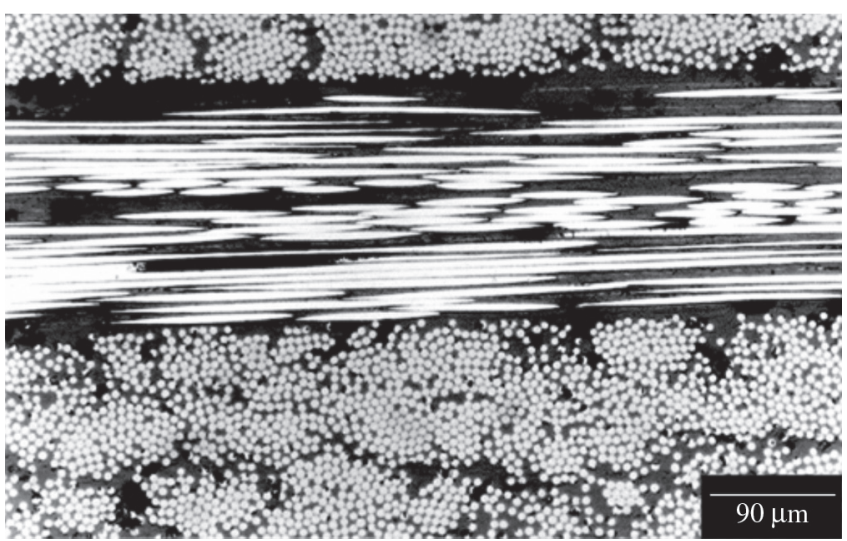

(a)

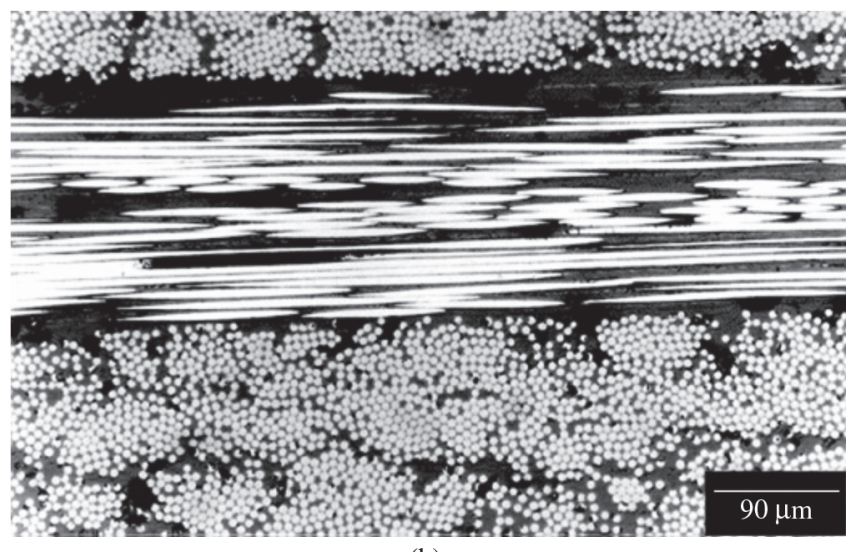

(b)

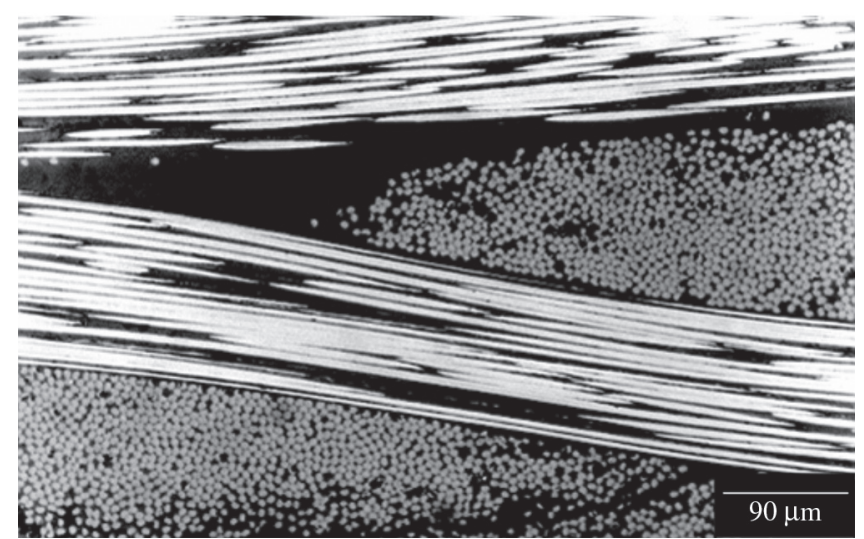

(c)

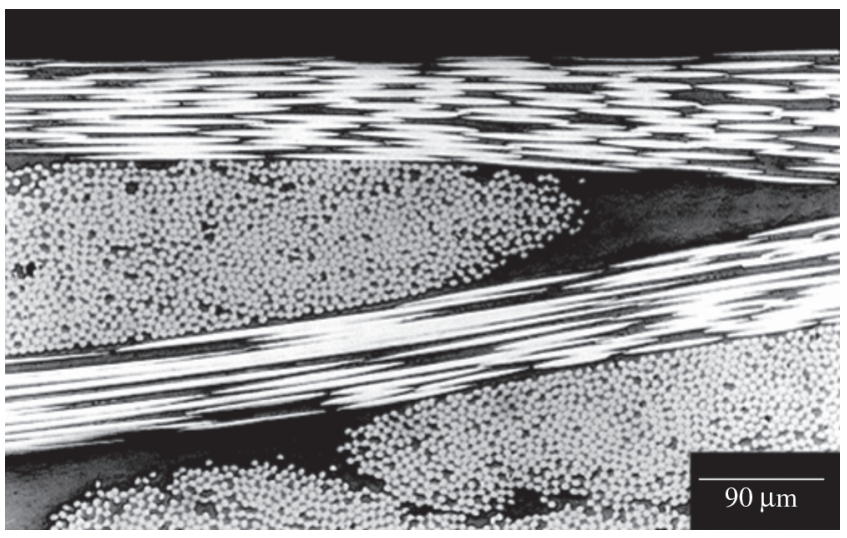

(d)

Figure 1. Cross-sectional microstructures of the tested carbon-epoxy laminates: a) TP120; b) TP180; c) FB120; and d) FB180. Typical carbon fiber diameter is $7 \mu \mathrm{m}$.

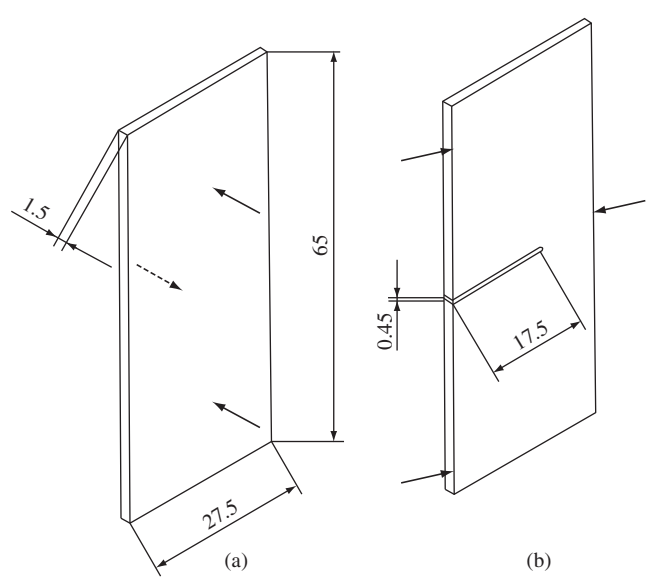

Figure 2. Tablet-shape test specimens: a) Un-notched for quasi-static transversal 3PB test; and b) Notched for 3PB translaminar impact testing. Dimensions are in $\mathrm{mm}$.

\section{Experimental Procedures}

Quasi-static 3PB tests were carried out at ambient temperature, under loading rates of 1 and $5 \mathrm{~mm} / \mathrm{min}$, respectively, in an EMIC ${ }^{\mathrm{TM}}$ testing system. Mechanical properties determined were Young's modulus $\left(\mathrm{E}_{\mathrm{b}}\right)$, flexural strength (FS) and tenacity at the maximum bending load $\left(\mathrm{TML}_{\mathrm{b}}\right)$.

Dynamic 3PB tests were also conducted at room temperature, in a semi-automated Charpy impact testing system specially adapted to accommodate wider and thinner test specimens. Likewise for the slow-bend experiments, a $40 \mathrm{~mm}$ span distance between the anvil supports was utilized. Two quite distinct dynamic loading conditions were employed in this study, corresponding to available impact energies of $5 \mathrm{~J}$ and $50 \mathrm{~J}$, respectively. The highest energy level was obtained by accelerating a $6,700 \mathrm{~g}$ hammer up to $3.80 \mathrm{~m} / \mathrm{s}$, whereas the lowest one by using a one-third-weight hammer accelerated up to half that velocity.

Typically, three specimens of each material were tested under both quasi-static and dynamic loading conditions. 


\section{Results and Discussion}

\subsection{Quasi-static 3PB tests}

Figure 3 plots maximum tensile stress developed at the surface ply as a function of the specimen deflection at the mid-span (load-line), obtained in the slow-bend tests, for the two loading rates imposed during the experiments.

Once the maximum strength of the testpiece is reached, the load invariably drops-off abruptly, with the test specimen displaying low (TP materials) or practically no residual resistances (FB laminates).

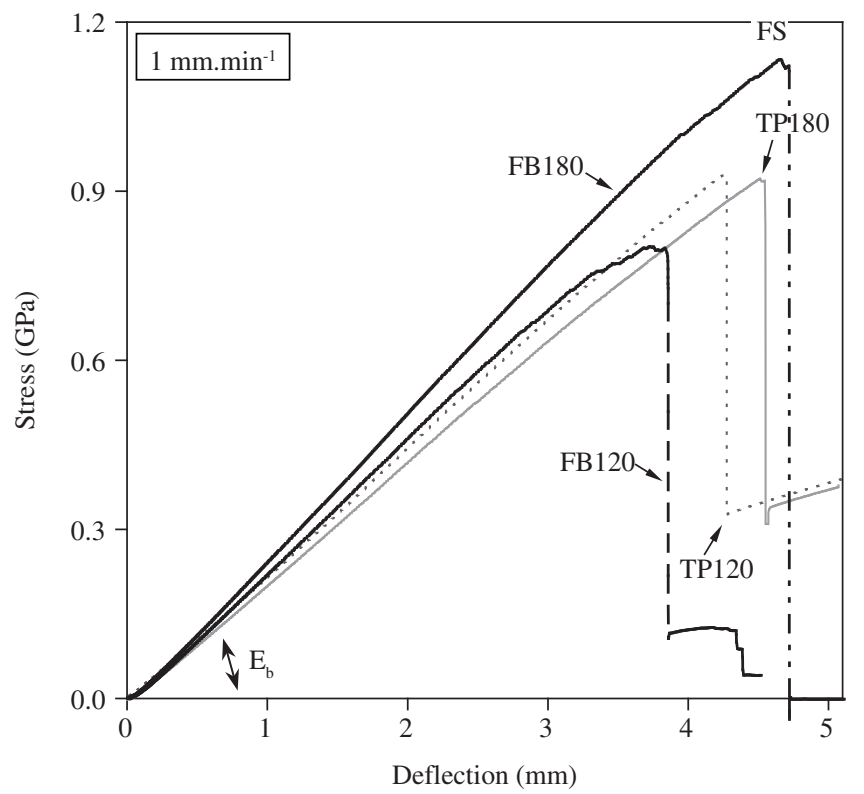

(a)

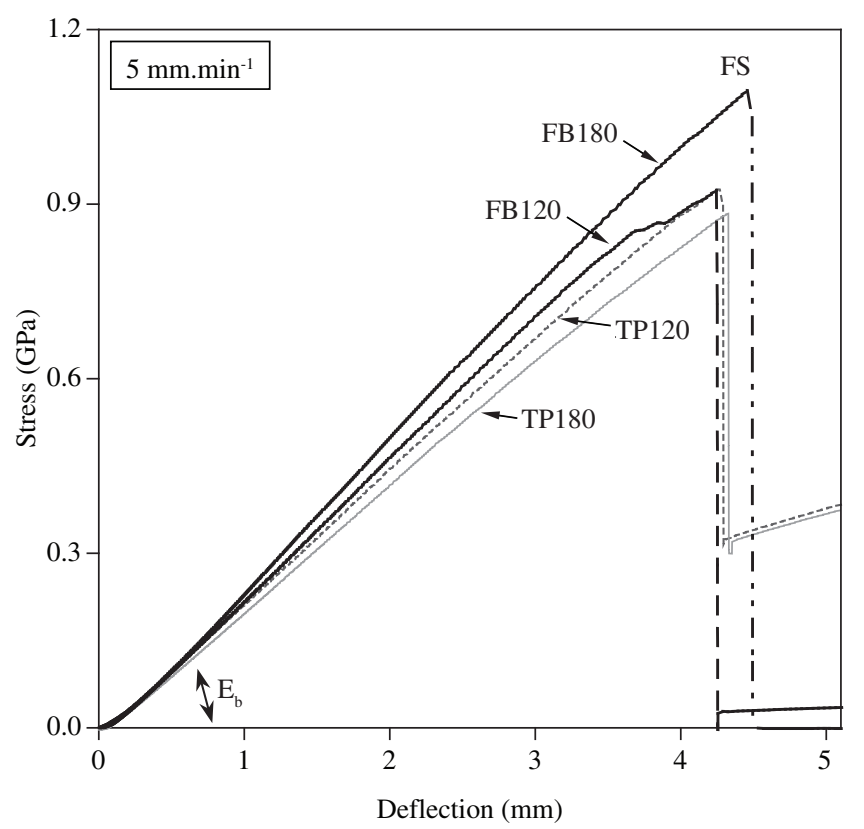

(b)

Figure 3. Typical stress-deflection curves for two applied loading rates: a) $1 \mathrm{~mm} / \mathrm{min}$; and b) $5 \mathrm{~mm} / \mathrm{min}$.
Due to the initial non-linearity of the load-deflection curves, the Young's modulus, $\mathrm{E}_{\mathrm{b}}$, was calculated within the range of 0.25 to $0.50 \mathrm{FS}$, where FS is the material's ultimate bending strength. The tenacity parameter, named $\mathrm{TML}_{\mathrm{b}}$, was obtained by numerical integration of the area under the curves plotted in Figure 3, up to the attainment of the maximum load, FS.

Table 2 lists the data obtained from slow 3PB tests, and Figure 4 presents the results in the form of relative performance of the materials tested. For this purpose, the mechanical properties have been normalized in regard to the minimum values attained during the experiments, which have been highlighted in Table 2 .

The main conclusions from Table 2 and Figure 4 can be summarized as follows:

\subsubsection{Modulus of elasticity, $\mathrm{E}_{\mathrm{b}}$}

- In general, fiber fabric-reinforced laminates performed better than angle-ply tape ones, with the laminate FB180-2 being

Table 2. Slow-bend test mean values at room temperature and two distinct loading rates. Standard deviation is provided in parenthesis.

\begin{tabular}{cccc}
\hline $\begin{array}{c}\text { Material code and } \\
\text { testing condition }\end{array}$ & $\mathrm{E}_{\mathrm{b}}(\mathrm{GPa})$ & $\mathrm{FS}(\mathrm{MPa})$ & $\mathrm{TML}_{\mathrm{b}}\left(\mathrm{kJ} / \mathrm{m}^{2}\right)$ \\
\hline TP120-1 & & & \\
TP120-2 & $38.2(2.3)$ & $933(59)$ & $1.993(128)$ \\
TP180-1 & $\mathbf{3 8 . 0 ( 2 . 6 )}$ & $932(62)$ & $1.984(119)$ \\
TP180-2 & $38.7(2.5)$ & $945(54)$ & $2.147(132)$ \\
FB120-1 & $39.0(2.3)$ & $892(53)$ & $1.976(110)$ \\
FB120-2 & $42.1(2.7)$ & $\mathbf{8 0 6}(\mathbf{5 0})$ & $\mathbf{1 . 5 7 7}(\mathbf{9 9})$ \\
FB180-1 & $48.4(3.2)$ & $937(59)$ & $2.065(155)$ \\
FB180-2 & $49.3(3.3)$ & $1.134(71)$ & $2.728(182)$ \\
\hline (1) $1 \mathrm{~mm} / \mathrm{min}$ & & & \\
(2) $5 \mathrm{~mm} / \mathrm{min}$ & & &
\end{tabular}

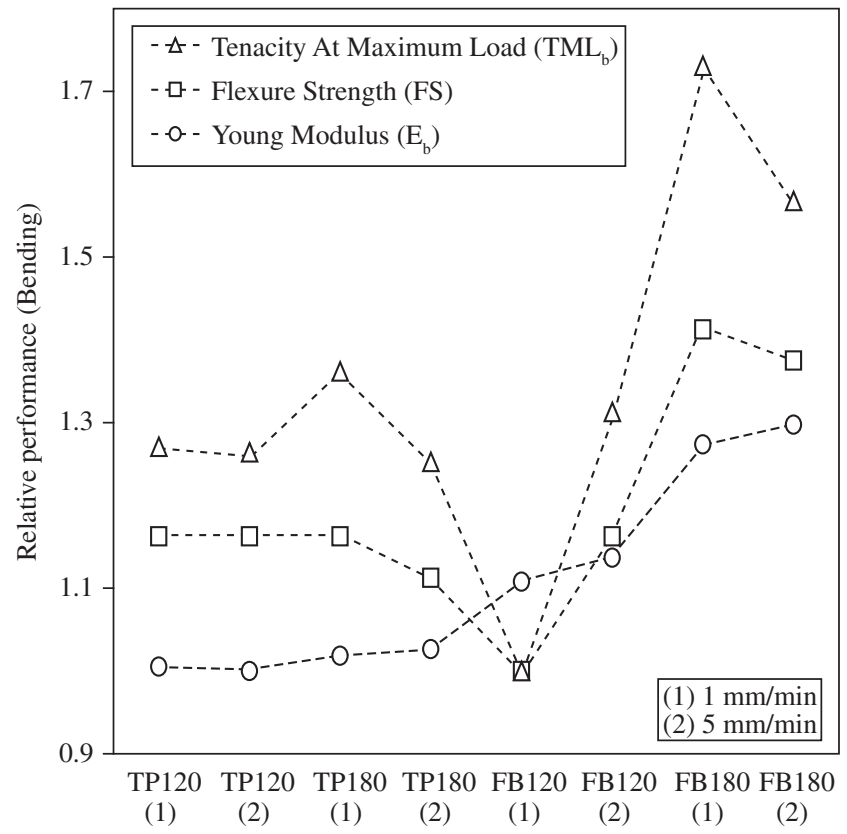

Figure 4. Relative (normalized) performance (based on mean results of Table 2) of the carbon-epoxy laminates under quasi-static bend loading at two different strain-rates. Point-to-point fits indicate the general trend of data only. 
the stiffest material. This conclusion disagrees with common experimental observations that cross-plied unidirectional tapes are stiffer than corresponding two-dimensional fabric configurations. Further investigation is needed to explain the unexpected, but consistent result obtained in this study;

- Higher cure temperature and pressure improved the performance of woven fabric laminates. This can be directly related to a reduced porosity content, and/or, to some extent, to the nature of the polymeric resin cured at $180{ }^{\circ} \mathrm{C}$ and $700 \mathrm{kPa}$, which is a rubber-toughened epoxy matrix;

- Woven fabric laminates performed better at higher loading rates, regardless the epoxy resin employed; and

- Maximum improvement on the mechanical performance of the laminates was achieved by shifting from tape to fiber fabric pre-form, changing from standard to rubber-toughened epoxy matrix, and applying the highest loading rate.

\subsubsection{Flexural Strength, FS}

- No noticeable effect on the performance of the fiber tape array was noticed due to the matrix resin nature, as well as the applied loading rate;

- Woven fabric architecture exhibited the best, FB180-1, and the worst, FB120-1, mechanical strength, indicating the vital role of the epoxy resin on this property;

- Rubber-toughened epoxy resin improved the mechanical performance of the fiber fabric array, especially at the lowest loading rate;

- Higher loading rates improved the performance of the FB120 composite, but otherwise were detrimental to both TP and FB laminates cured at $180{ }^{\circ} \mathrm{C}$, signalizes again the key role played by the epoxy resin employed on the laminate manufacturing; and

- Maximum improvement on the mechanical performance of the laminates was achieved with the woven fiber configuration tested at $1 \mathrm{~mm} / \mathrm{min}$, by shifting from standard to rubber-toughened polymeric resin.

\subsubsection{Tenacity at the Maximum Load, $\mathrm{TML}_{\mathrm{b}}$}

- The beneficial effect provided by the use of rubber-toughened resin with the fiber tape array was off-set by the detrimental effect of increasing the loading rate; and

- Except for the aforementioned effect, the tenacity parameter, $\mathrm{TML}_{\mathrm{b}}$, followed the same pattern as flexural strength property, FS.

The experimental results exposed above indicate that the carbon fiber fabric pre-form impregnated with rubber-toughened epoxy resin is mechanically superior to any other fiber/resin combination.

\subsection{Dynamic 3PB tests}

The experimental results from impact tests are presented in Table 3 . Notice that the impact absorbed energy parameter, IAE, was normalized in regard to the original ligament area of the specimens tested $\left(15 \mathrm{~mm}^{2}\right)$, so that this toughness property denotes specific fracture energies, i.e., energy per unit area of fracture.

Figure 5 plots Table 3 data in terms of relative performance of the materials tested. Likewise in Figure 4, results provided in Figure 5 were normalized with respect to the minimum value obtained during the mechanical experiments, which has been shaded in Table 3.

The main conclusions from Table 3 and Figure 5 can be summarized as follows:

- Under the lightest (and slowest) impact condition (5 J) the employed epoxy resin exerted only a moderate effect on the
Table 3. Mean results of impact tests under 3PB conditions at room temperature and two available energy levels for the mechanical shock. Standard deviation is provided in parenthesis.

\begin{tabular}{cc}
\hline $\begin{array}{c}\text { Material code and } \\
\text { testing condition }\end{array}$ & $\operatorname{IAE}\left(\mathrm{kJ} / \mathrm{m}^{2}\right)$ \\
\hline TP120-1 & \\
TP120-2 & $167(9)$ \\
TP180-1 & $172(12)$ \\
TP180-2 & $166(9)$ \\
FB120-1 & $157(6)$ \\
FB120-2 & $171(11)$ \\
FB180-1 & $\mathbf{1 0 7}(\mathbf{6})$ \\
FB180-2 & $215(11)$ \\
${ }_{(1)} \mathrm{v}=\mathrm{v}_{\max }=3.80 \mathrm{~m} / \mathrm{s} ; \mathrm{m}=\mathrm{m}_{\max }=6,700 \mathrm{~g}(50$ Joules of full available energy); \\
and ${ }^{(2)} \mathrm{v}=\mathrm{v}_{\text {max }} / 2 ; \mathrm{m}=\mathrm{m}_{\text {max }} / 3$ (5 Joules of full apportioned energy).
\end{tabular}

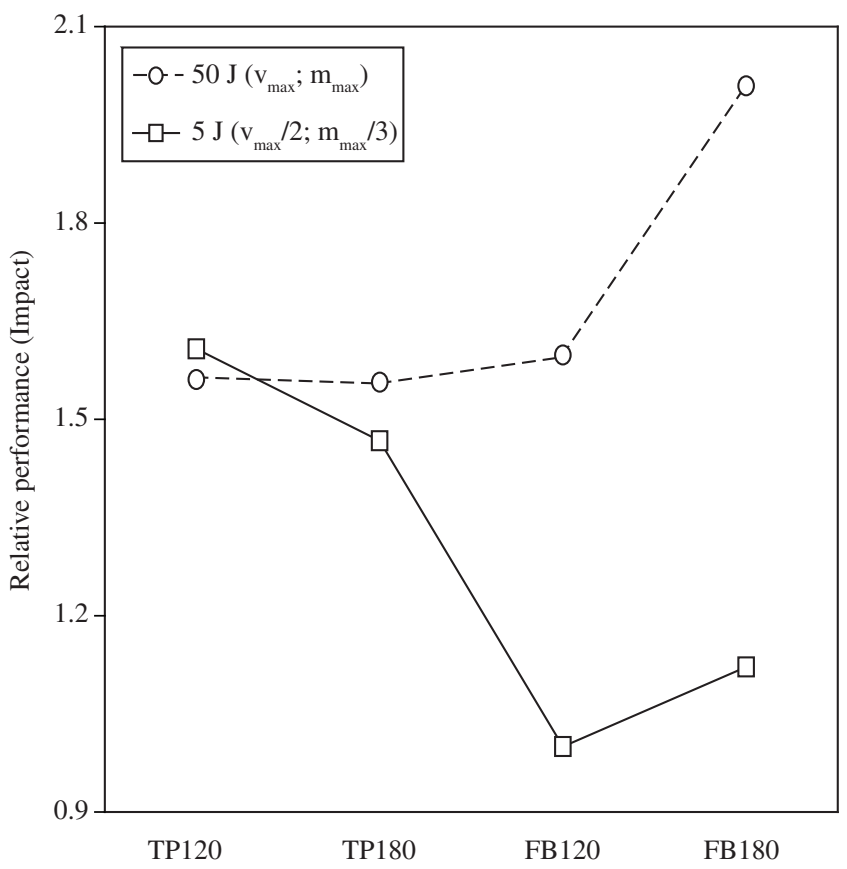

Figure 5. Relative impact performance (based on mean results of Table 3) of the carbon-epoxy laminates, for two different testing conditions. Point-to-point fits indicate the general trend of data only.

dynamic response of both classes of laminates. On the other hand, under the heaviest (and fastest) shock condition (50 J), the rubber-toughened resin added a very positive effect on the performance of the fabric array;

- During the 5 Joules dynamic testing the cross-ply tape array performed much better than the bidirectional fabric configuration, regardless the utilized epoxy resin. This behavior was previously noticed by Zanetti et al. ${ }^{8}$ during non-linear translaminar fracture toughness testing of these materials. The possible explanation remains the same, and presupposes that delamination is the main energy absorption mechanism of the laminates, which is facilitated in the fiber tape layered array since it contains much more delamination interfaces than corresponding fabric arrangement; and 
- Fiber fabric arrays exhibited overriding dynamic strain-rate sensitiveness, regardless the epoxy resin utilized, whereas tapereinforcing laminates are practically loading-rate insensitive.

These results grant the carbon fiber fabric pre-form impregnated with rubber-toughened epoxy resin as the best option to operate in the high-energy impact regimen. However, this laminate should be avoided in the low energy impact regimen, when tape performs embedded in either standard or rubber-toughened resin grades should be preferable.

\subsection{Fractographic analysis}

Shown in Figures 6a-6d are the topographical aspects exhibited by 3 PB impacted specimens, which presented the maximum and the minimum dynamic fracture resistances, respectively (see Figure 5). It can be promptly observed that the laminates developed very distinct levels of fiber debonding and pullout mechanisms. In this sense, the toughest material, FB180, presented scarce regions with these micro-mechanisms of fracture, whereas they widespread on the FB120 fracture surface. The shallower rupture aspect of the reinforcing phase in the former material signalizes that more effective dynamic fracture energy absorption mechanisms are mainly based on the typically high tensile loading capacity of the carbon fibers, instead of fiber debonding and pullout evolvements. In this sense, the rubber-toughened resin seems to promote a stronger fiber/matrix interface adhesion compared to the standard epoxy resin, which can be related to some extent to its higher cure temperature and pressure.

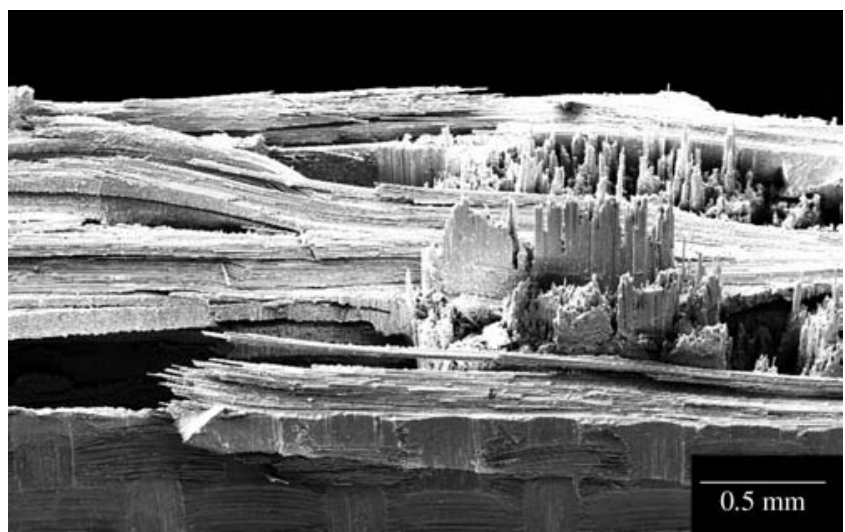

(a)

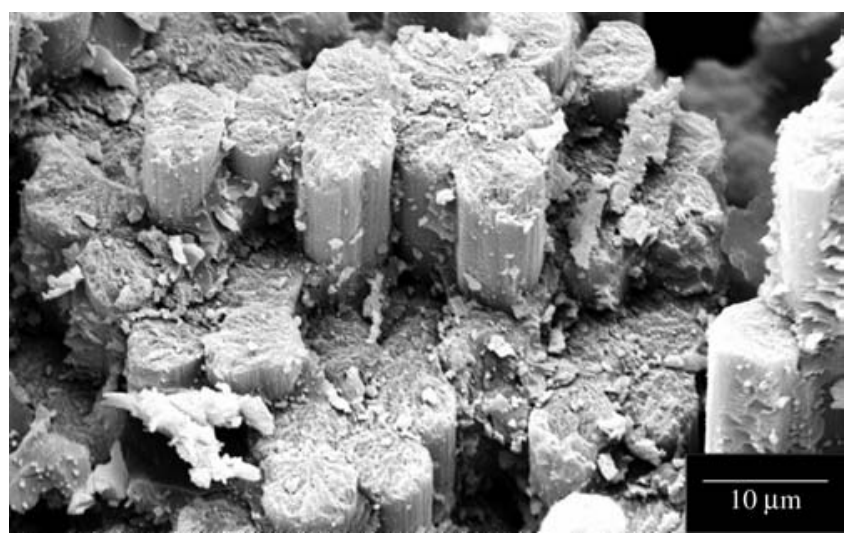

(b)

\section{Concluding Remarks}

In this study, quasi-static and impact bending properties of four aeronautical grade carbon-epoxy composite laminates have been determined and compared.

The obtained results have been interpreted on the basis of microstructural characteristics exhibited by the materials tested, e.g., carbon fiber array (cross-ply unidirectional tape vs. bidirectional woven fabric), type of epoxy resin (standard $v s$. rubber-toughened grade), as well as testing conditions applied on their mechanical assessment, e.g., loading rate and available impact energy.

All evaluated mechanical properties have shown to be sensitive to the abovementioned variables, rendering them (mechanical properties) reliable criteria for composite materials selection aiming at optimize the in-test and in-service performances of aeronautical structures and components.

It has been concluded that two-dimensional woven carbon fiber reinforcement embedded in rubber-toughened epoxy resin, which constitutes the most expensive fiber/resin combination, should be selected to operate under quasi-static (transversal mode loading) and high-energy impact (translaminar mode loading) conditions. That is to say, the mechanical performance promoted by the rubber-toughened resin off-sets its high costs. However, this study has also shown that great care should be taken in applying this material in the low-energy impact regimen of typically 5 Joules.

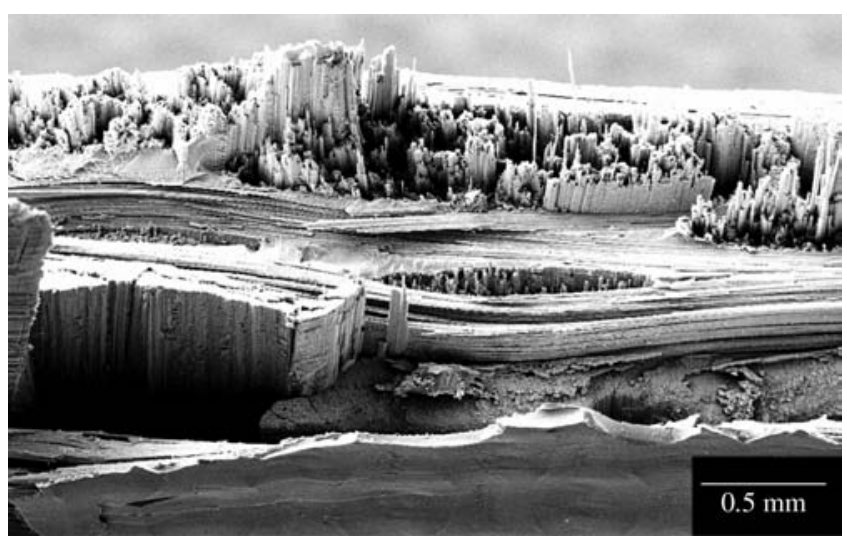

(c)

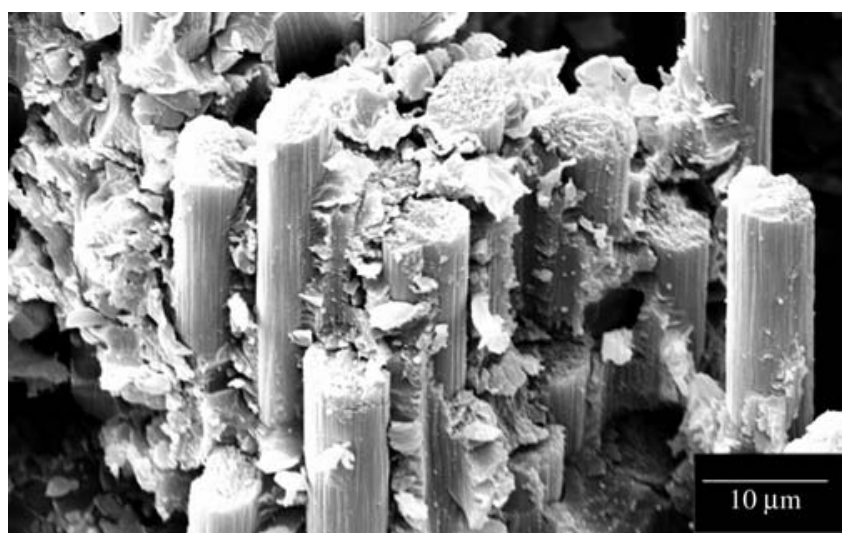

(d)

Figure 6. SEM-fractographs of specimens fractured under impact loading: a,b) Maximum dynamic toughness exhibited by fiber fabric configuration (FB180) tested under 50 Joules; and c,d) Minimum impact resistance displayed by fiber fabric array (FB120) tested under available energy of 5 Joules. 


\section{Acknowledgments}

The authors wish to express their gratitude to Embraer S/A for providing the materials tested. The laboratorial assistance supplied by the student C. E. G. de Castro is also deeply appreciated.

\section{References}

1. Harrington A, Reed J. A look into the next decade, Armade International, 1986; 7(6):345-353.

2. Niu MCY. Airframe structural design. Wanchai: Hong Kong Conmilit Press; 1988.

3. Niu MCY. Composite airframe structures. Wanchai: Hong Kong Conmilit Press; 1992.

4. Middleton DH. Composite materials in aircraft structures. London: Longman Scientific and Technical; 1990.

5. Agarwal BD, Broutman LJ. Analysis and performance of fiber composites. New York: John Wiley \& Sons; 1991.

6. Hoskin BC, Baker AA. Composite materials for aircraft structures. New York: AIAA Education Series; 1986.

7. Tarpani JR, Milan MT, Spinelli D. Mechanical Performance of Carbonepoxy Laminates - Part II: Quasi-static and Fatigue Tensile Properties. Materials Research. 2006; 9(2):125-134.

8. Zanetti D, Bose WW, Tarpani JR. Tenacidade à fratura dinâmica de compósitos carbono-epóxi. In: Congresso Anual da Associação Brasileira de Metalurgia e de Materiais, 2004, São Paulo, BR. São Paulo: ABM; 2005. p. 1486-1496.

\section{Appendix}

$\mathrm{FS}=3 \mathrm{Q}_{\mathrm{m}} \mathrm{S} / 2 \mathrm{wt} \mathrm{t}^{2}$

$$
\mathrm{E}_{\mathrm{b}}=\mathrm{S}^{3} \mathrm{Q} / 4 \mathrm{wt} \mathrm{t}^{3} \delta
$$

where $\mathrm{Q}_{\mathrm{m}}$ is the maximum load, $\mathrm{S}$ is the span distance between the anvil supports of the $3 \mathrm{~PB}$ jig, $0.04 \mathrm{~m}, \mathrm{w}$ is the specimen width, $0.0275 \mathrm{~m}$, t is its thickness, $0.0015 \mathrm{~m}$, and $\delta$ is the deflection measured along the load-line.

\section{Nomenclation}

$\mathrm{E}_{\mathrm{b}} \quad$ Young's modulus under bend loading, GPa

EMIC trade-mark of testing machine

FB fiber fabric array

FS flexural strength, MPa

IAE impact absorbed energy, $\mathrm{kJ} / \mathrm{m}^{2}$

$\mathrm{m}_{(\max )}$ (maximum) pendulum mass, $\mathrm{g}$

$\mathrm{Q}_{\mathrm{m}} \quad$ maximum load, GN

$\mathrm{S} \quad$ span distance, $\mathrm{m}$

SEM scanning electron microscopy

$\mathrm{t}$ specimen thickness, $\mathrm{m}$

$\mathrm{TML}_{\mathrm{b}}$ tenacity at the maximum bending load, $\mathrm{kJ} / \mathrm{m}^{2}$

TP fiber tape array

$\mathrm{v}_{(\max )} \quad$ (maximum) pendulum velocity, $\mathrm{m} / \mathrm{s}$

$\mathrm{W}$ specimen width, $\mathrm{m}$

$\delta \quad$ load-line deflection, $m$

3PB three-point bend testing

\section{Subscripts}

$b \quad$ relative to bend loading

max relative to maximum value

$\mathrm{S} \quad$ relative to symmetrical 